\title{
Growth Hormone Induces Transforming Growth Factor-Beta-Induced Protein in Podocytes: Implications for Podocyte Depletion and Proteinuria
}

\author{
P. Swathi Chitra, ${ }^{1}$ T. Swathi, ${ }^{1}$ Rakesh Sahay, ${ }^{2}$ G. Bhanuprakash Reddy, ${ }^{1 *}$ \\ Ram K. Menon, ${ }^{3}$ and P. Anil Kumar ${ }^{4 * *}$ \\ ${ }^{1}$ National Institute of Nutrition, Hyderabad, India \\ ${ }^{2}$ Osmania General Hospital, Hyderabad, India \\ ${ }^{3}$ Pediatric Endocrinology and Molecular and Integrative Physiology, University of Michigan, Ann Arbor, MI \\ ${ }^{4}$ Department of Biochemistry, University of Hyderabad, Hyderabad, India
}

\section{ABSTRACT}

The glomerular podocytes form a major size selective barrier for the filtration of serum proteins and reduced podocyte number is a critical event in the pathogenesis of proteinuria during diabetic nephropathy (DN). An elevated level of growth hormone (GH) is implicated as a causative factor in the development of nephropathy in patients with type 1 diabetes mellitus. We have previously shown that podocytes express GH receptor and are a target for GH action. To elucidate the molecular basis for the effects of GH on podocyte depletion, we conducted PCR-array analyses for extracellular matrix and adhesion molecules in podocytes. Our studies reveal that GH increases expression of a gene that encodes transforming growth factor-beta-induced protein (TGFBIp) expression. Similarly, microarray data retrieved from the Nephromine database revealed elevation of TGFBIp in patients with DN. Treatment with GH results in increased secretion of extracellular TGFBIp by podocytes. Both GH and TGFBIp induced apoptosis and epithelial mesenchymal transition (EMT) of podocytes. Exposure of podocytes to GH and TGFBIp resulted in increased migration of cells and altered podocyte permeability to albumin across podocyte monolayer. Administration of GH to rats induced EMT and apoptosis in the glomerular fraction of the kidney. Therefore, we conclude that the GH-dependent increase in TGFBIp in the podocyte is one of the mechanisms responsible for podocyte depletion in DN. J. Cell. Biochem. 116: 1947-1956, 2015. ๑ 2015 Wiley Periodicals, Inc.

\section{KEY WORDS: GROWTH HORMONE; PODOCYTEs; TGFBIP; ZEB2; E-CADHERIN}

$\mathrm{D}$ iabetic nephropathy (DN), characterized by increased glomerular permeability to serum proteins, is the most common cause of end-stage renal disease (ESRD) [Kumar et al., 2013]. The three components; fenestrated endothelium of glomerular capillaries, the glomerular basement membrane (GBM), and the visceral glomerular epithelial cells (podocytes) constitute the glomerular filtration apparatus, which is permeable to water and small dissolved solutes and offers size selective filtration for the larger molecules [Anil Kumar et al., 2014]. Podocytes are terminally differentiated epithelial cells that regulate glomerular permselectivity, synthesize components of GBM, and counteract the intraglomerular hydrostatic pressure. Podocytes form interdigitating foot processes with bridging slit-diaphragms to regulate renal ultra-filtration and prevent loss of high molecular weight serum proteins into urine. Normal renal filtration is dependent on the integrity of interaction between podocyte and GBM and an adequate number of podocytes [Anil Kumar et al., 2014]. Podocyte depletion is considered as a hallmark of glomerular diseases including DN [Anil Kumar et al., 2014; Nakamura et al., 2000; Shankland, 2006]. Podocyte depletion could be the result either apoptosis and/or podocyte detachment from the GBM [Wolf et al., 2005]. Human biopsy studies indicate that podocytes are injured very early in the pathogenesis of DN

Conflict of interest: All authors state that there is no conflict of interest.

Grant sponsor: Department of Science and Technology; Grant numbers: IFA11-LSBM-02, SB/FT/LS-307/2012, SR/ WOS-A/LS-474/2013.

*Correspondence to: G. Bhanuprakash Reddy, National Institute of Nutrition, Hyderabad, India. E-mail: bhanu@ ninindia.org

***Correspondence to: P. Anil Kumar, Department of Biochemistry, University of Hyderabad, Hyderabad, India. E-mail: pakumarsl@uohyd.ernet.in

Manuscript Received: 6 November 2014; Manuscript Accepted: 27 February 2015

Accepted manuscript online in Wiley Online Library (wileyonlinelibrary.com): 4 March 2015

DOI 10.1002/jcb.25150 • (C) 2015 Wiley Periodicals, Inc. 
[Wolf et al., 2005]. Decreased expression of podocyte proteins such as nephrin and podocin has been documented in experimental models of nephropathy [Aaltonen et al., 2001]. Although several mechanisms that result in podocyte damage in DN have been proposed, a complete understanding of the molecular and cellular mechanism(s) mediating podocyte loss in DN is lacking.

The pathogenesis of DN is complex and an array of factors have been suggested as potential contributors to podocyte damage in diabetes mellitus [Anil Kumar et al., 2014]. One of the axis that have been implicated in DN is the GH-IGF1 axis [Christiansen et al., 1981; Cummings et al., 1998; Kumar et al., 2011]. Progression to ESRD is associated with abnormalities in pituitary growth hormone $(\mathrm{GH})$ secretion and diminished renal clearance of GH [Tonshoff et al., 1995]. Children with ESRD have an increased number of secretory bursts of $\mathrm{GH}$ compared to children with normal renal function [Tonshoff et al., 1995]. Definite evidence for a causal role of GH in nephropathy has come from acromegalic subjects wherein excess GH levels were associated with significant structural and functional changes in the kidney and albuminuria [Baldelli et al., 2008; Manelli et al., 2000]. In case of mice transgenic for bovine $\mathrm{GH}$, glomeruli was disproportionately enlarged paralleled with glomerulosclerosis and increased albumin: creatinine ratio [Doi et al., 1990]. Experimental animals with hyperactivity of the GH-axis exhibit podocyte damage and poor renal function [Kumar et al., 2011]. In contrast, GH-deficient dwarf rats had minimal proteinuria, mild renal functional impairment and moderate renal histological scarring [El Nahas et al., 1991]. In our earlier studies, we demonstrated that podocytes express the GH receptor [Reddy et al., 2007] and respond to GH by inducing the expression of ZEB2 that results in decreased expression of P- and E-cadherins [Kumar et al., 2010].

One of the abnormalities from patients with diabetes mellitus is loss of podocytes [Verzola et al., 2007]. The urinary sediments from patients with proteinuric diseases including DN contain increased levels of podocyte markers [Sato et al., 2009; Kalani et al., 2013]. Interaction between podocytes and GBM is critical to the normal renal filtration since podocytes anchor to GBM and regulate glomerular permselectivity. Perturbations in various components of extracellular matrix (ECM) are associated with DN [Mason and Wahab, 2003; Kolset et al., 2012]. However, the effect of GH on cell-adhesion and ECM components that determine podocyte-GBM integrity is unclear. In this study we investigated the effect of GH on expression of ECM and adhesion molecules of podocytes. Gene expression profiling of mouse podocytes by PCRarray identified GH dependent up-regulation of transforming growth factor-beta-induced protein (TGFBIp). TGFBIp is also known as beta induced gene human clone 3 (BIGH3) and is a 68$\mathrm{kDa}$ extracellular matrix protein and it has been postulated to be involved in cell-matrix interaction and cell migration [Bae et al., 2002; Kim et al., 2003b]. In a recent study, it was reported that TGFBIp promotes metastasis of colon cancer by enhancing cell extravasation [Ma et al., 2008]. TGFBIp also mediates TGF $\beta$ evoked apoptosis [Zamilpa et al., 2009]. It is considered that TGFBIp elicits both epithelial mesenchymal transition (EMT) and apoptosis. Our present study indicates a role for TGFBIp in transducing the effect of GH on the podocytes.

\section{MATERIALS AND METHODS}

\section{CULTURING OF PODOCYTES}

Conditionally immortalized mouse podocyte (MPC-5) cells were maintained under growth-permissive conditions at $33^{\circ} \mathrm{C}$ and $5 \%$ $\mathrm{CO}_{2}$. RPMI-1640 medium containing 10\% FBS, 100 units $/ \mathrm{ml}$ of penicillin, $100 \mu \mathrm{g} / \mathrm{ml}$ of streptomycin, and $10 \mathrm{units} / \mathrm{ml}$ of mouse $\gamma$ interferon (Sigma) were used to maintain MPC-5 cells in proliferating condition. To induce differentiation, podocytes were shifted to non-permissive conditions at $37^{\circ} \mathrm{C}$ without $\gamma$-interferon for 10 days. Differentiated podocytes were maintained for $12-16 \mathrm{~h}$ in serum-free medium before treating with hGH (Pfizer) or pegvisomant (Pfizer) or rTGFBIp (R\&D Systems).

\section{PCR-ARRAY ANALYSIS}

MPC- 5 cells were harvested after $48 \mathrm{~h}$ of treatment with or without $\mathrm{GH}(500 \mathrm{ng} / \mathrm{ml})$. Total RNA was isolated, purified using RNeasy kit (QIAGEN) and subjected to first-strand cDNA synthesis. The expression of 84 genes associated with ECM and adhesion molecules was profiled using cDNA isolated from podocytes employing $\mathrm{RT}^{2}$ Profiler PCR Array (http://www.sabiosciences.com/genetable.php? pcatn=PAMM-013A). The protocol and data analysis were performed according to manufacturer's instructions.

\section{REAL-TIME QUANTITATIVE PCR ASSAY}

Total RNA was extracted and purified from MPC- 5 cells treated with or without GH (500 ng/ml) or TGFBIp ( $5 \mu \mathrm{g} / \mathrm{ml})$. Quantitative PCR was performed using QuantiTect SYBR Green RT-PCR kit (QIAGEN) with 7000 Prism detection system (ABI). mRNA expression of each gene was normalized using the expression of GAPDH that was used as an internal control.

\section{ESTIMATION OF TGFBIP BY ELISA}

GH dependent secretion of TGFBIp was estimated by stimulating podocytes with $\mathrm{GH}(500 \mathrm{ng} / \mathrm{ml})$ for varying time periods ranging from 12-48 h. Spent culture media from podocytes exposed to $\mathrm{GH}$ was collected at each time point and centrifuged at $200 \times \mathrm{g}$ for $5 \mathrm{~min}$ at $4^{\circ} \mathrm{C}$. Supernatants so obtained were used to measure TGFBIp using sandwich-ELISA with mouse monoclonal antibody against TGFBIp (REtD Systems) as a capture antibody and biotinylated goat antibody against TGFBIp (REtD Systems) as the detection antibody. Streptavidin-horseradish peroxidases followed by o-phenylenediamine dihydrochloride were added to initiate the color reaction and the reactions were then stopped with sulfuric acid and read at $490 \mathrm{~nm}$. Recombinant human TGFBIp was used as a standard.

\section{WHOLE CELL LYSIS AND IMMUNOBLOTTING}

MPC- 5 cells were treated with or without GH or TGFBIp for specified time periods. Cells were washed with ice-cold PBS and lysed using $1 \mathrm{X}$ cell lysis (RIPA) buffer supplemented with protease inhibitor mixture (Roche). Cell lysate was subjected to centrifugation at $12000 \times \mathrm{g}$ for $15 \mathrm{~min}$ to collect the supernatant, which was processed for SDS-PAGE and immunoblotting. All antibodies used in this study were procured from cell-signaling technologies and used in 1:1,000 dilutions. When indicated, the membrane was then stripped and reblotted with anti-tubulin antiserum (Sigma; 1:1,000) to verify equality of sample loading. 


\section{CELL DEATH ANALYSIS}

For cell death analysis, podocytes were treated with GH for varying period of time ranging from $12-72 \mathrm{~h}$. At each time point, the floating and attached cells were harvested and used for the enumeration of viable and nonviable cells. Cells were reconstituted in fresh media and an equal volume of trypan blue (0.4\%) solution was added. Cells were counted using hemocytometer and light microscope. The number of viable (unstained) cells and nonviable (stained) cells were enumerated and expressed as a percentage of total number of cells (always $\geq 500$ cells) counted. TUNEL assay (ApoAlert; Clontech) was performed to determine the apoptosis of MPC-5 cells treated with GH or TGFBIp. Podocytes were cultured on cover slips and treated with GH or TGFBIp for indicated time periods. Cells were washed with PBS and fixed with $4 \%$ formaldehyde for $25 \mathrm{~min}$ at $4^{\circ} \mathrm{C}$, permeabilized with $0.2 \%$ Triton $\mathrm{X}-100$ for $5 \mathrm{~min}$ on ice, and incubated with a mixture of nucleotides and TdT enzyme for $60 \mathrm{~min}$ at $37^{\circ} \mathrm{C}$ in humidified chamber. Reaction was terminated with a solution containing $300 \mathrm{mM}$ sodium chloride and $30 \mathrm{mM}$ sodium citrate, and the cover slips were mounted on glass slides. Apoptotic nuclei were detected under fluorescence microscope with characteristic morphology of nuclear fragmentation and nuclear condensation. A total of 100 cells were counted for each sample.
Results were expressed as the percentage of apoptotic cells. Detection of caspase-3 activity was performed with ApoAlert Caspase Colorimetric Assay Kit (Clontech). Differentiated podocytes were treated with or without TGFBIp and harvested. Equal number of cells were resuspended in lysis buffer and centrifuged at $12,0008 \times \mathrm{g}$ for $10 \mathrm{~min}$ at $4^{\circ} \mathrm{C}$. Supernatant was collected and incubated with caspase3 substrate Acetyl-DEVD-p-nitroaniline $(50 \mu \mathrm{M})$ at $37^{\circ} \mathrm{C}$ for $1 \mathrm{~h}$; and the absorbance was measured at $405 \mathrm{~nm}$.

\section{SCRATCH ASSAY}

Mouse podocytes were seeded in 6 well plates and grown under normal growth conditions to reach upto 95\% confluence. When the cells are ready, media was aspirated and a scratch was made using a pipette tip. The scratch should be made in the form of "+" in a smooth sweeping motion. Cells were washed twice with pre-warmed media in order to remove any debris from damaged cells. Images of cells were taken before and after treating with GH or TGFBIp at a regular time points to monitor the rate at which the denuded area of cells get colonized by the surrounding migrating cells. The area covered by cells is quantified using Image $\mathrm{J}$ software (NIH, Bethesda, MD) and represented as the percent area coverage (Cell Area/ROI Area $\times 100$ ).

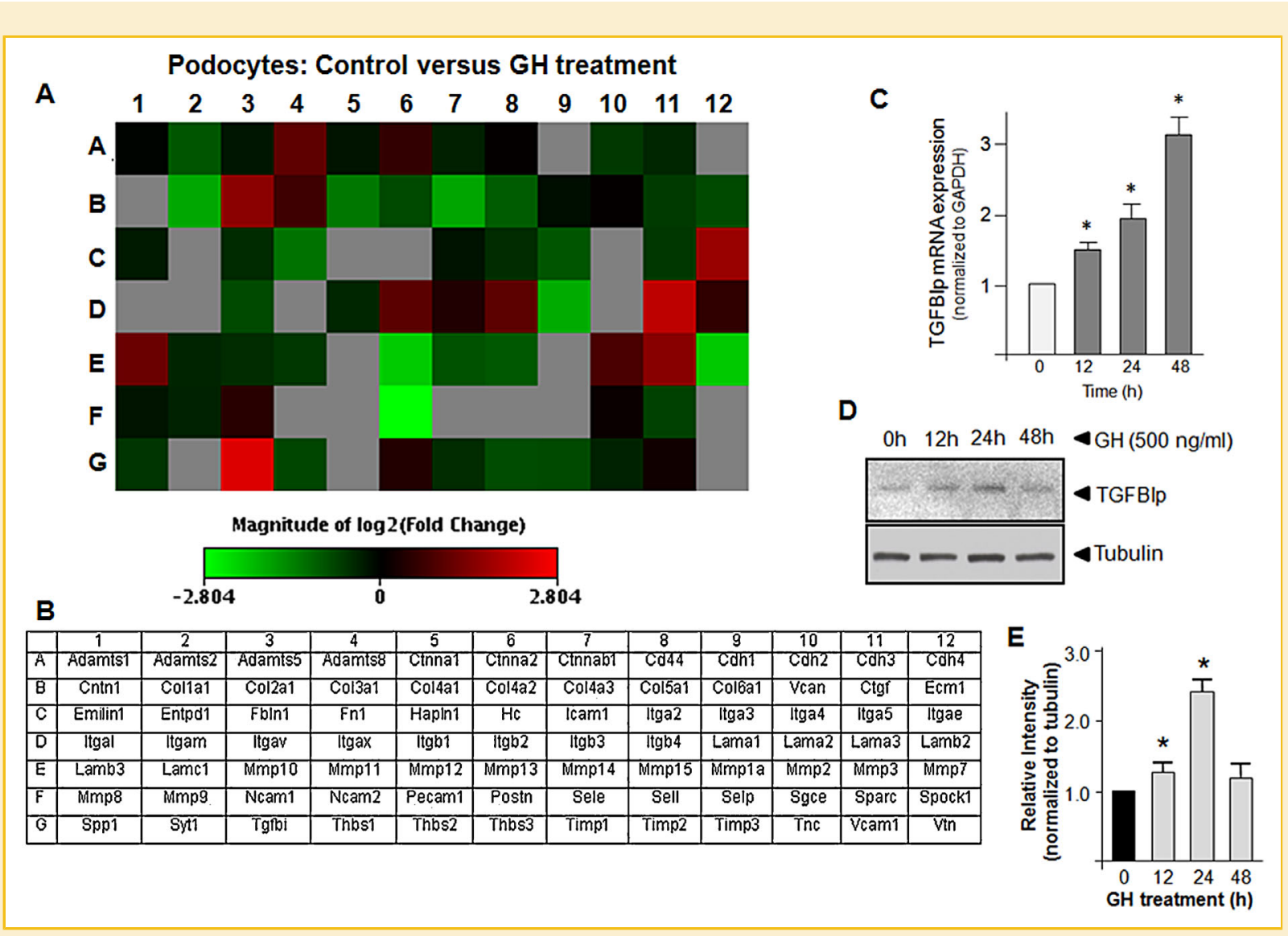

Fig. 1. GH dependent expression of TGFBlp in glomerular podocytes. A: Differentiated mouse podocytes (MPC-5 cells) were treated with or without GH for $48 \mathrm{~h}$, RNA was isolated and PCR-array (Qiagen \#PAMM-013) was performed and heat map was obtained. B: Outline of PCR-array plate. G3 well indicates expression of TGFBI C: Expression of TGFBlp transcript in podocytes treated with GH $(500 \mathrm{ng} / \mathrm{ml})$ for indicated time periods. The data are depicted as mean $\pm \mathrm{SE}$ and "denotes expression of TGFBlp under GH stimulus were different from that under control conditions with $P<0.05 ; \mathrm{n}=5$. D: A representative immunoblot for TGFBlp and tubulin from podocytes treated with GH ( $500 \mathrm{ng} / \mathrm{ml}$ ) for the indicated time periods. E: Densitometric quantification of TGFBIp expression normalized to tubulin. Data are means \pm SE of three times experiments, ${ }^{\circ} P<0.05$. 


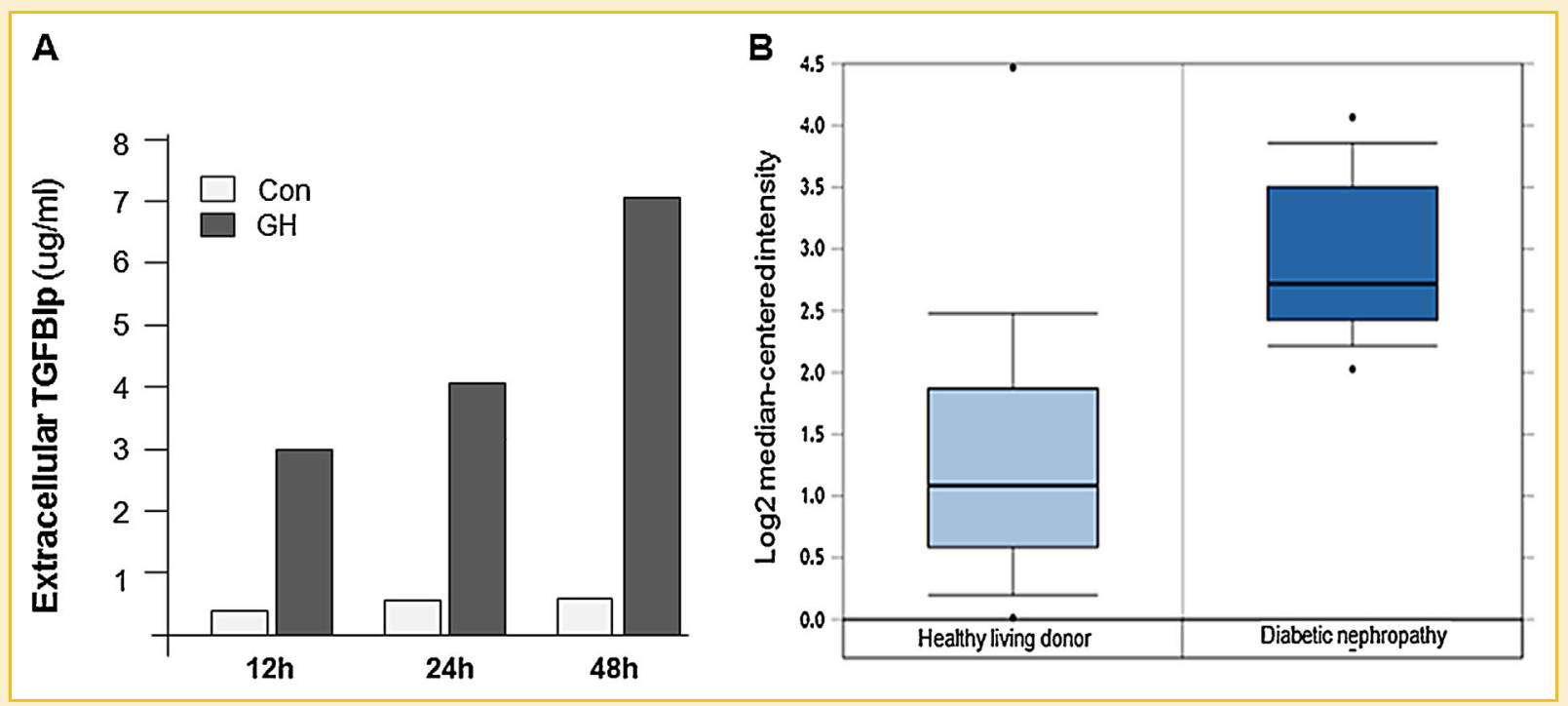

Fig. 2. GH induces extracellular secretion of TGFBIp. A: Differentiated mouse podocytes were treated with GH for indicated time periods and spent culture media collected. Clarified supernatant was used to estimate TGFBIp content by sandwich ELISA as described in methods. B: Meta-analysis of TGFBIp mRNA expression in glomeruli from healthy living donor $(n=41)$ and DN patients $(n=12)$ using Nephromine ${ }^{T M}$. Over expression gene rank 109 (top 1\%); reporter 201506_at; $P$ value: $4.02 E-7 ; t-T e s t-6.325$, and fold change 2.934. Nephromine (Life Technologies, Ann Arbor, MI) was used for analysis and visualization.

\section{ALBUMIN INFLUX ASSAY}

MPC- 5 cells were plated on a 12-well plate and differentiated at nonpermissive conditions as described above by culturing for 10 days. The cells were then treated with either $\mathrm{GH}(500 \mathrm{ng} / \mathrm{ml})$ or TGFBIp $(5 \mu \mathrm{g} / \mathrm{ml})$ for $24 \mathrm{~h}$ essentially as described earlier [Han et al., 2010]. Subsequently, the medium was removed, and cells were washed twice with a $1 \mathrm{mM} \mathrm{CaCl}_{2}$ and $1 \mathrm{mM} \mathrm{MgCl}_{2}$ mixture to preserve cadherin junctions. Two milliliters of RMPI 1640 medium with $40 \mathrm{mg} / \mathrm{ml}$ BSA was then placed in the bottom chamber, and $0.3 \mathrm{ml}$ of RPMI 1640 medium (without albumin) was placed in the top chamber. The cells were incubated at $37^{\circ} \mathrm{C}$, aliquots of medium were collected from the top chamber at various (1-, 2-, and 4-h) time points, and albumin concentration was measured in these aliquots using the bicinchoninic acid protein assay kit (SigmaAldrich).

\section{ANIMAL EXPERIMENT}

Expression of EMT markers was examined in glomeruli isolated from rats injected with GH. Adult female Wistar rats (body weight $200 \mathrm{~g}$ ) were used in this study. Individual rats were housed in a cage and placed in a pathogen free facility with a $12: 12 \mathrm{~h}$ artificial light cycle. Temperature and humidity were kept in a controlled range. The animals had free access to standard chow and drinking water throughout the experiment. Experimental rats $(n=6)$ received a single i.p dose of hGH $1.5 \mathrm{mg} / \mathrm{kg} /$ day for two weeks whereas control rats $(n=6)$ have received an equal volume of saline. Prior to sacrificing, the animals were placed in individual metabolic cages for determination of 24-h urine volume, glucose, creatinine and albumin. For histopathology assessment, kidneys were perfused and fixed with alternating intra-aortic injections of PBS $(0.02 \mathrm{M}, \mathrm{pH}$ 7.4) and 10\% neutral-buffered formalin until blanching of kidneys was achieved. All experimental procedures were approved by the University of Hyderabad institutional Animal Care and Use Committee.

\section{KIDNEY LYSATE PREPARATION}

Under general anesthetia, kidneys were perfused with PBS containing $50 \mathrm{U} / \mathrm{ml}$ sodium heparin through a cannula placed in the abdominal aorta. Hydrostatic pressure during perfusion was kept constant at $100 \mathrm{mmHg}$ and perfusion was carried out till the kidneys were blanched. Following perfusion with PBS, the left kidney was ligated and the right kidney was perfused with $50 \mathrm{ml}$ of ferric oxide slurry in PBS via the abdominal aorta. The right kidney with ironcontaining glomeruli was minced and glomeruli isolated by a technique modified from that of Meezan et al. Isolated glomeruli were further subjected to homogenization with lysis buffer containing protease inhibitors mixture and used for immunoblotting.

\section{IMMUNOHISTOCHEMICAL ANALYSIS}

Both paraffin-embedded and cryosections of kidneys from control and experimental rats were prepared. Paraffin-embedded sections were deparaffınized with xylene and rehydrated through a descending ethanol gradient. Hemotoxylin and eosin staining was performed to examine the morphology. Immunostaining for WT-1 and synaptopodin (Santa Cruz Biotechnology, Dallas, TX) was performed in paraffin embedded sections and cryosections, respectively. The number of podocytes per glomerulus was determined by counting the number of WT-1 expressing cells in each glomerulus from paraffin sections. Each slide (15 glomeruli per section and $n=5$ per group) were observed independently by three investigators blinded to the identity of the paraffin section. 


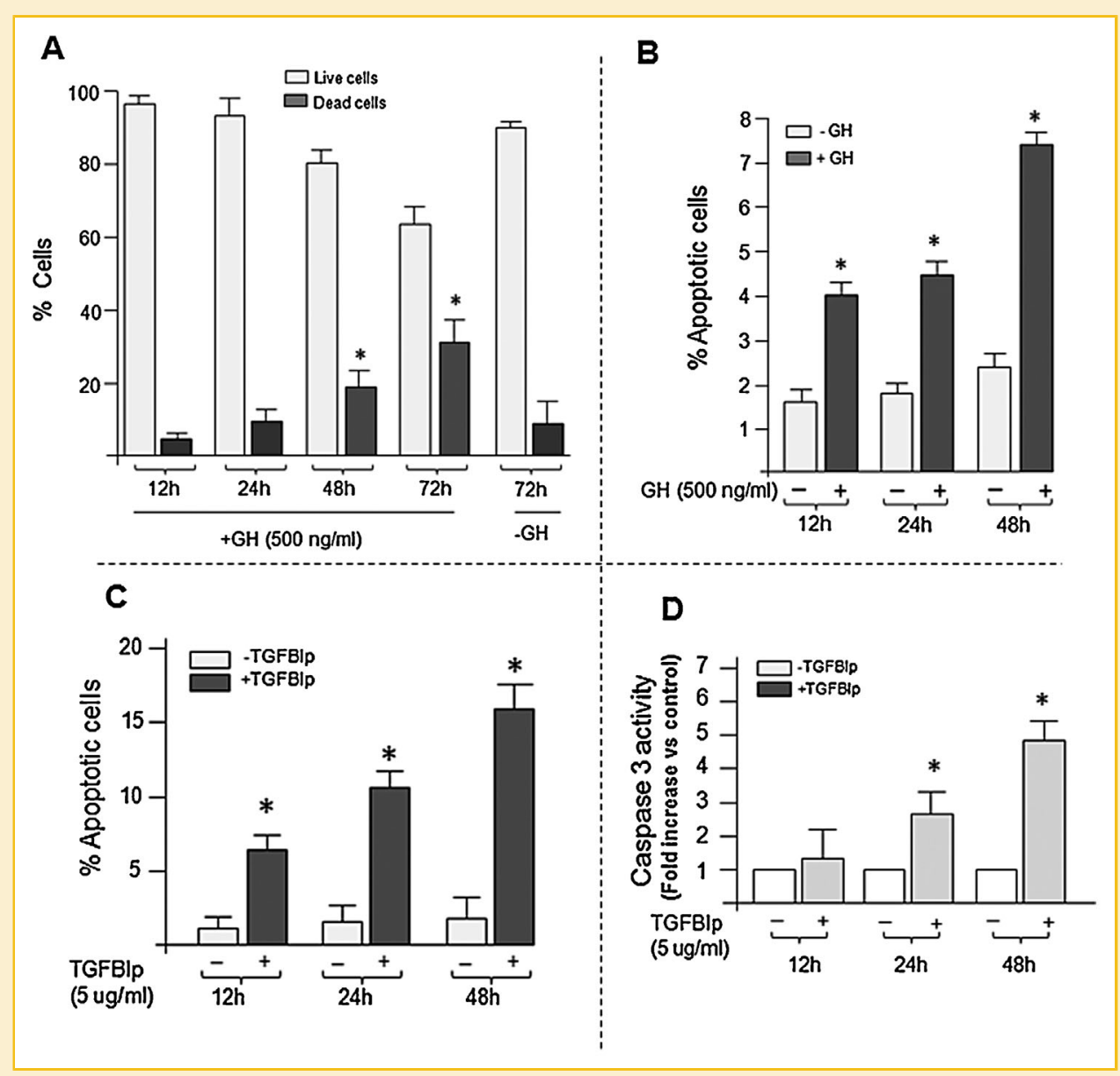

Fig. 3. GH and TGFBIp induce cell death. A: Differentiated mouse podocytes were treated with GH for indicated time periods. Cells were harvested and stained with trypan blue and cell count was performed and data presented as \% live cells versus dead cells. Differentiated mouse podocytes were treated with (B) either GH or (C) TGFBlp and TUNEL assay was performed. TUNEL positive cells were counted and expressed as \% of apoptotic cells. (\%) Apoptotic cells=number of TUNEL positive staining cells/number of total cells $\times 100 \%$ (at least 100 cells were counted for each sample). D: Caspase 3 substrate assay was performed in mouse podocytes treated with TGFBlp and its activity was expressed in relation to control. The data are depicted as mean \pm SE. denotes $P<0.05(n=5)$ for exposure to GH or TGFBlp vs control for the specified parameter.

\section{STATISTICAL ANALYSIS}

Data are presented as mean \pm SE. SPSS software (SPSS, Inc.) was used to apply Mann-Whitney and Kruskal-Wallis nonparametric tests to analyze statistical differences between the distributions of two or multiple independent samples, respectively. $P$ values $\leq 0.05$ were considered significant.

\section{RESULTS}

\section{GH INCREASES TGFBIP EXPRESSION IN PODOCYTES}

We used PCR array analysis to conduct a survey of the effect of GH on the expression of genes that encode ECM and adhesion molecules in the podocytes. Expression of transforming growth factor-betainduced gene (TGFBI, also known as BigH3) was elevated with $\mathrm{GH}$ treatment along with other members of ECM and adhesion molecules including collagen type II $\alpha 1$, integrin E, laminin $\alpha 3 / \beta 3$, and MMP-3 (G3 well of Fig. 1A and B and Fig.S1A). The fold expression of all the genes tested was provided in Table S1. TGFBI encodes for TGFBI- protein (TGFBIp), which is also called Bigh3 protein or keratoepithelin. Results obtained from PCR array analysis were confirmed with quantitative real time RT-PCR measurement of the steady state abundance of TGFBI mRNA. For this purpose, MPC-5 cells were exposed to $\mathrm{GH}$, and mRNA was harvested at various time periods. These experiments revealed that levels of TGFBIp mRNA were increased 1.5- (12 h), 1.9- $(24 \mathrm{~h})$, and 3.1-fold (48 h) following exposure of podocytes to GH (Fig. 1C). Immunoblotting of lysates from podocytes exposed to GH revealed time-dependent increase in the levels of TGFBIp protein (Fig. 1D and E). Further, we have tested whether this up-regulation of TGFBIp in podocytes was specific to $\mathrm{GH}$ or not in the presence of $\mathrm{GH}$ receptor (GHR) antagonist, pegvisomant. Pegvisomant ameliorated GH induced TGFBIp expression in podocytes (Fig. S1B). TGFBIp is an extracellular matrix protein and secreted by cells. Therefore, we estimated TGFBIp levels in spent culture media of podocytes that were exposed to $\mathrm{GH}$. Exposure of podocytes to $\mathrm{GH}$ resulted in an increased secretion of TGFBIp with increased levels up to seven folds at $48 \mathrm{~h}$ of exposure compared with cells that were naïve to $\mathrm{GH}$ treatment (Fig. 2A). 


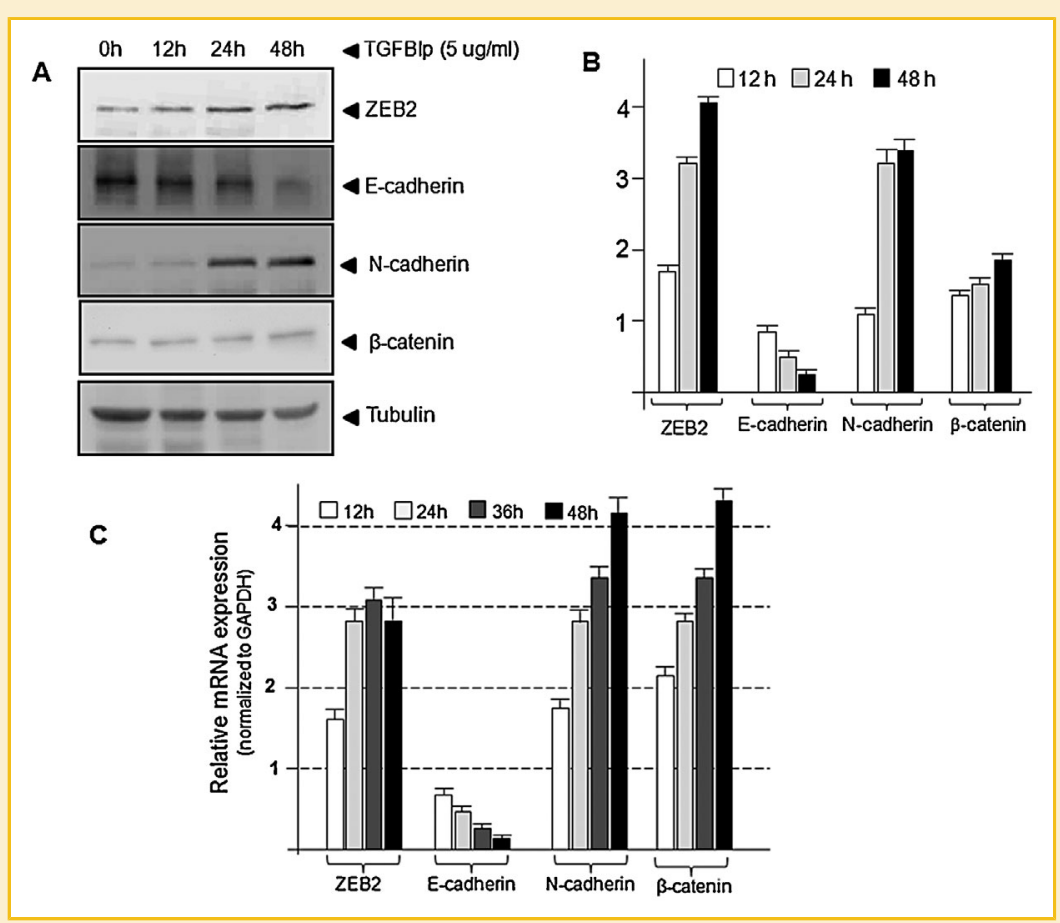

Fig. 4. TGFBIp induces EMT markers in podocytes. Differentiated mouse podocytes were treated with or without TGFBIp ( 5 ug/ml) for indicated time periods and cell lysates were processed for immunoblotting or RNA isolation. A: Representative immunoblots showing the expression of EMT markers in TGFBlp treated podocytes. B: Densitometric quantification of EMT markers normalized to tubulin. Expression of marker in untreated cells $(0 \mathrm{~h})$ considered as one fold. The results are shown as mean $\pm S E$. ( $\left.n=3,{ }^{*}, P<0.05\right)$. C: Expression of EMT markers in TGFBIp treated podocytes as analyzed by RT-PCR with mRNA expression in control cells considered as one fold. The results are shown as mean \pm SE for $n=4$ and $P<0.05$.

Further, we utilized the online database, www.nephromine.org that provides curated data from genome-wide expression studies to compare expression of TGFBIp in humans with DN. We identified that expression of TGFBIp is higher in glomeruli from DN patients compared to healthy donors (Fig. 2B).

\section{GH INDUCES CELL DEATH IN PODOCYTES}

As evidenced by PCR-array analysis and confirmed by RT-PCR and immunoblotting, GH induces TGFBIp expression in podocytes. We next investigated the consequence of GH dependent TGFBIp expression in podocytes. Multiple evidences suggest that TGFBIp induces cell death by apoptosis in a variety of cells including retinal pericytes, CHO cells, and osteosarcoma cells [Kim et al., 2003a; Zamilpa et al., 2009; Han et al., 2010]. We therefore studied the effect of GH and TGFBIp on podocyte cell death. GH induced time dependent cell death in podocytes (Fig. 3A). Following $12 \mathrm{~h}$ of exposure to $\mathrm{GH}$ there was only a marginal decrease in viable cell count, whereas $24 \mathrm{~h}, 48 \mathrm{~h}$, and $72 \mathrm{~h}$ exposure to $\mathrm{GH}$ the percent of live cells was decreased by 12\%, 19\%, and 35\%, respectively (Fig. 3A). By employing TUNEL assay, we have confirmed the mode of cell death in GH treated podocytes to be apoptosis (Fig. 3B). Analogously, podocytes treated with TGFBIp also underwent apoptosis and it was found that TGFBIp is more effective than GH in inducing apoptosis of podocytes at concentrations tested (Fig. 3C). Increased activity of caspase- 3 revealed that TGFBIp induced cell death by apoptosis (Fig. 3D).

\section{GH INDUCES EPITHELIAL MESENCHYMAL TRANSITION (EMT) IN PODOCYTES}

It has been posited that podocyte dedifferentiation and EMT could be a potential mechanism resulting in podocyte dysfunction and decreased count thus playing a causal role in the pathogenesis of proteinuric diseases [Li et al., 2008]. TGFBIp promotes invasion of tumor cells via EMT [Nummela et al., 2012; Ween et al., 2011]. Therefore, we assessed the expression of EMT markers in GH treated podocytes and observed induction of ZEB2, which is known to play a key role in EMT process (Fig. S2 A and B). In addition, we found that exposure to $\mathrm{GH}$ resulted in decreased E-cadherin, increased Ncadherin, and $\beta$-catenin expression (Fig. S2 ACtB). Further, mRNA analysis also revealed decreased E-cadherin, increased $\mathrm{N}$-cadherin, and $\beta$-catenin expression (Fig. S2C). In similar to GH treatment, exposure of podocytes to TGFBIp also resulted in increased ZEB2, Ncadherin, $\beta$-catenin, and decreased E-cadherin expression in podocytes (Fig. 4A-C).

\section{GH AND TGFBIP INDUCE PODOCYTE MIGRATION AND ALTER FILTRATION BARRIER FUNCTION}

To assess the functional consequence of effect of GH and TGFBIp on podocytes, we examined whether these molecules induce migration of podocytes employing a popular scratch assay. Our experiments revealed that both GH and TGFBIp induce migration of cells and TGFBIp is more effective than GH in inducing podocyte migration (Fig. 5A and B). Furthermore, to assess the consequence of podocyte 


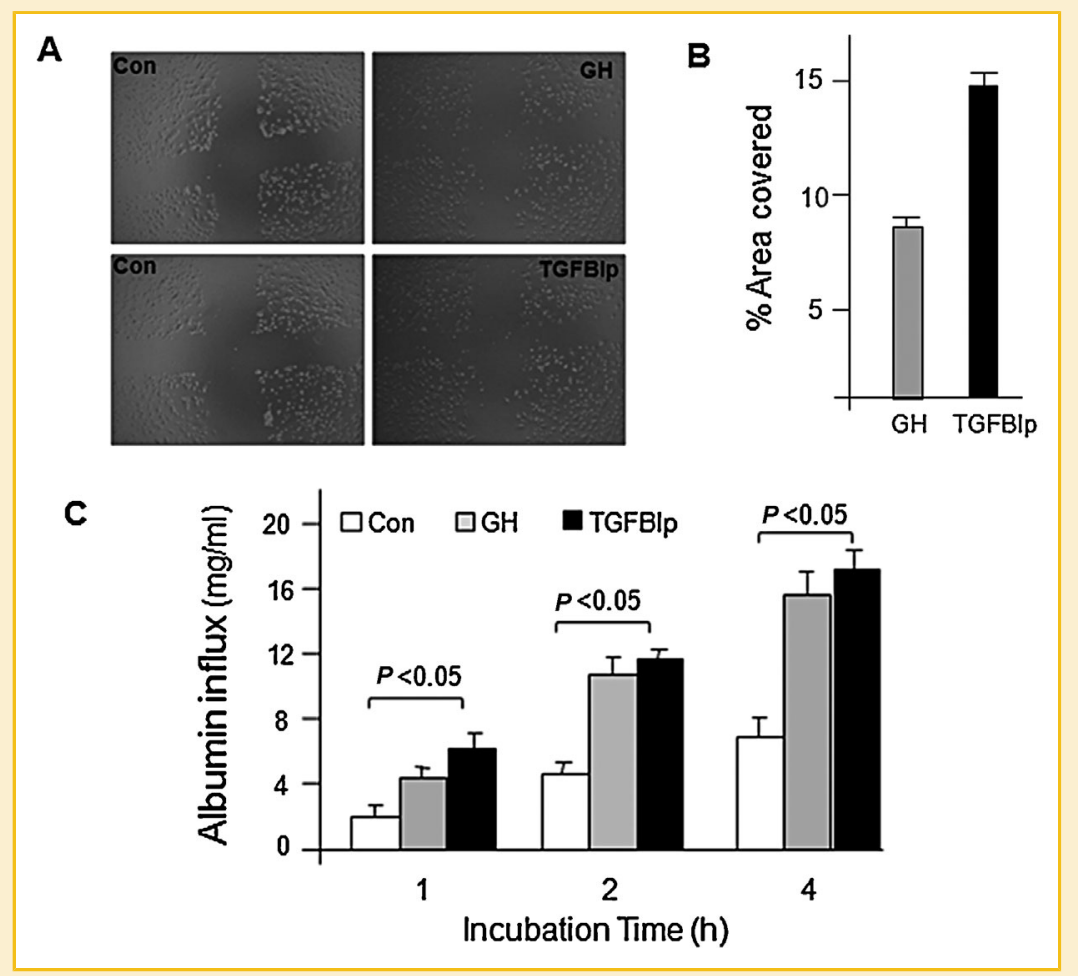

Fig. 5. GH and TGFBIp induces podocyte migration and alters permeability. Differentiated mouse podocytes were grown under nonpermissive conditions as described in methods section and scratched in "+" shape with a sterile yellow pipette tip. Following washing cells were treated with or without GH (500 $\mathrm{ng} / \mathrm{ml}$ ) or TGFBlp ( 5 $\mu \mathrm{g} / \mathrm{ml}$ ) for $2 \mathrm{~h}$. A: A representative images of podocytes treated with or without GH/TGFBIp for $2 \mathrm{~h}$. B: \% area covered with cells after treating damaged cells with GH or TGFBIp for $2 \mathrm{~h}$ whereas area of original wound is considered a $100 \%$. C: Differentiated mouse podocytes (MPC- 5 cells) were grown under nonpermissive conditions as a monolayer and treated with GH ( $500 \mathrm{ng} /$ $\mathrm{ml}$ ) or TGFBIp ( $5 \mu \mathrm{g} / \mathrm{ml})$ for $24 \mathrm{~h}$, and albumin permeability across the podocyte monolayer was determined at 1, 2, and $4 \mathrm{~h}$ following the $24 \mathrm{~h}$ exposure to GH or TGFBlp. Error bars indicate mean $\pm S E ; n=4$.

exposure to GH on its filtration barrier function, we employed paracellular permeability assay that measures the rate of albumin flux across the podocyte monolayer [Li et al., 2008; Kumar et al., 2010]. For these experiments, podocytes were cultured on transwell filters and exposed to GH or TGFBIp for $24 \mathrm{~h}$ and the influx of BSA across the podocyte monolayer was measured. These results reveal that both GH and TGFBIp increase albumin influx across the podocyte monolayer (Fig. 5C). However, at the concentrations tested, TGFBIp dependent increase in albumin efflux was greater than that observed for GH (Fig. 5C). Increased permeability of podocytes to albumin suggests reduced podocyte integrity upon treatment with GH or TGFBIp.

\section{GH ADMINISTRATION PROMOTES DECREASED PODOCYTE COUNT IN WISTAR RAT KIDNEY}

To validate the effect of GH on podocyte viability and EMT in vivo, we injected rats with $\mathrm{GH}$ for 2 weeks and isolated glomeruli from kidney. Upon immunoblotting analysis, we found that treatment with GH resulted in increased ZEB2, N-cadherin and $\beta$-catenin, and decreased E-cadherin expression (Fig. 6A). Interestingly, we also found elevated expression of TGFBIp in GH treated rats (Fig. 6A). We have also noticed increased $\mathrm{p} 21$ and decreased $\mathrm{BCl} 2$ in glomerular fraction of $\mathrm{GH}$ treated rats (Fig. 6A). Decreased staining for synaptopodin in glomeruli from GH treated rats revealed reduced podocyte density (Fig. 6B). Hematoxylin and eosin (HAE) reveal altered morphology of glomeruli in GH treated rats as evidenced by thickening of basement membrane, mesangial sclerosis, and interstitial infiltration (Fig. 6C). GH treated rats also showed significantly decreased podocyte count compared with control rats (Fig. 6D). We collected 24h urine from control and GH treated rats and estimated albumin and creatinine. We found that albumin: creatinine ratio was increased in rats treated with GH (Fig. 6E).

\section{DISCUSSION}

Our studies reveal that GH increases the levels of TGFBIp, an extracellular matrix protein in podocytes. Both, GH and TGFBIp induced apoptosis and EMT in podocytes and altered podocyte permselectivity. Furthermore, we show that chronic administration of GH to rats results in increased expression of TGFBIp and induction of EMT in the glomerulus with concomitant decrease in the podocyte count and proteinuria. These observations support a role for increased GH levels, and GH-dependent increase in TGFBIp in the causation of podocyte depletion and albuminuria in Type1 diabetes.

Podocyte number and integrity is critical for the maintenance of normal glomerular filtration [Anil Kumar et al., 2014]. Proteinuria is a hallmark of DN and studies have indicated that decreased podocyte 


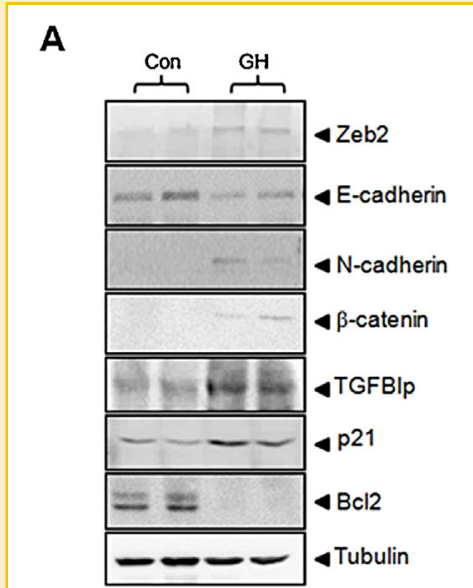

B

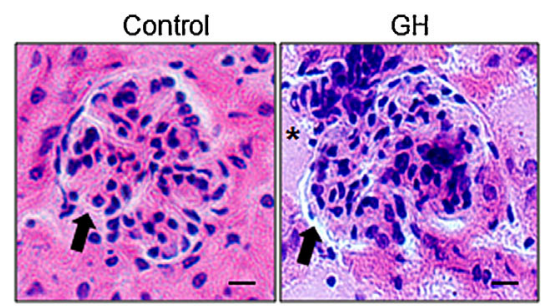

B

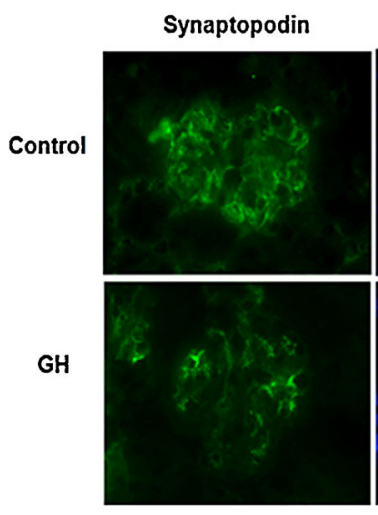

D

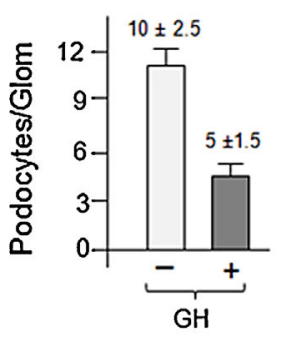

DAPI

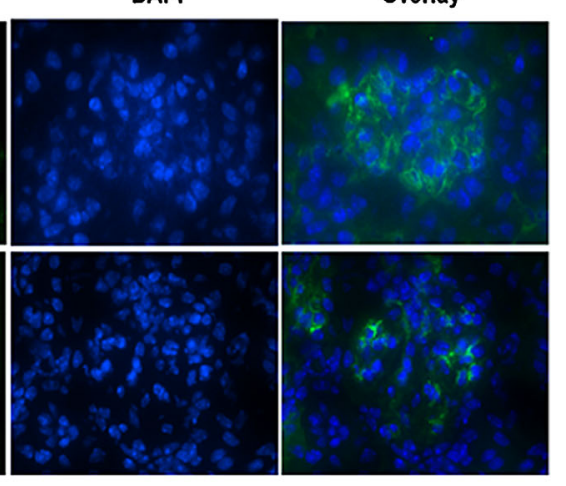

E

Fig. 6. In vivo administration of GH induces EMT and podocyte depletion. A: Expression of EMT and apoptotic markers in glomeruli from rats treated with GH for 2 weeks. B: Immunofluoresnce detection of synaptopodin expression in control and $\mathrm{GH}$ treated rat glomeruli $\mathrm{C}$ : $\mathrm{HCtE}$ staining of control and $\mathrm{GH}$ treated rat glomeruli. Increased thickening of basement membrane (arrows), mesangial sclerosis and interstitial infiltration $\left(^{*}\right)$ was noticed in $\mathrm{GH}$ treated rats. D: Number of podocytes per glomeruli from control and $\mathrm{GH}$ injected rats were counted from WT-1 stained paraffin sections from control and GH-treated rats. E: Urinary albumin/creatinine ratio was measured from urine collected for $24 \mathrm{~h}$ from control and GH treated rats. Error bars indicate mean \pm SE $(n=6$, denotes $P<0.05)$.

count is a key feature of DN. Circulating levels of GH are elevated in type 1 diabetes and elevated GH is one of the factors implicated in the pathogenesis of DN. In type 1 diabetes, insulin deficiency results in impaired hepatic IGF-1 production, which via negative feedback mechanism stimulate pituitary gland to secrete more GH, thus resulting in a higher circulatory levels of $\mathrm{GH}$ in diabetic patients [Edge et al., 1990]. GH excess in both humans and in transgenic animal models is characterized by significant structural and functional changes in the kidney [Kumar et al., 2011]. Analogously, states of GH deficiency or ablation of GH receptor (GHR) or its activity confer a protective effect against DN [Kumar et al., 2011]. An earlier study from our group revealed that podocytes express GHR and respond to GH by activation of JAK/STAT signaling [Reddy et al., 2007]. It was also demonstrated that podocytes respond to $\mathrm{GH}$ by inducing expression of ZEB2, a transcription factor that mediates EMT [Kumar et al., 2010]. However, the molecular mediator of GH's action on podocytes is not known. Therefore, we studied the effect of $\mathrm{GH}$ on expression profile of extracellular matrix and adhesion molecules and identified increased expression and extracellular secretion of TGFBIp in GH treated podocytes.

TGFBIp was first identified in an A549 (lung adenocarcinoma) cell line treated with TGF- $\beta$ [Skonier et al., 1992]. TGFBIp is a secretory protein of $68 \mathrm{kDa}$ with an $\mathrm{N}$-terminal secretory signal sequence, four
"Fas-1-like" domains homologous to Drosophila fasciclin and a Cterminal "arginine-glycine-aspartate" (RGD) motif. TGFBIp interacts with various extracellular matrix proteins to promote attachment, migration, proliferation, and differentiation in a wide range of cells by interacting with integrins via the RGD motif [Thapa et al., 2005]. Hence, TGFBIp has also been termed as RGD-collagen associated protein (RGD-CAP). TGFBIp is expressed in a wide variety of tissues including cornea, skin, tendon, endometrium and, kidney [Ween et al., 2012]. TGFBIp mutations have been linked to corneal epithelial and stromal dystrophies [Kannabiran and Klintworth, 2006]. The physiological function of TGFBIp is postulated to involve cell-matrix interactions to form an organized structure that supports normal cell morphogenesis.

Our results indicate that GH stimulates TGFBIp expression in podocytes. Since interaction between podocytes and GBM is critical for normal renal function, aberrant expression of TGFBIp is expected to exert a deleterious effect on the podocytes and result in impaired glomerular filtration. Further, our studies reveal that treating podocytes with TGFBIp results in both apoptosis and EMT, thus, results in podocytopathy. Increased expression of TGFBIp has been reported in Type 1 DM model [Gilbert et al., 1998]. Placed in the context of elevated GH levels in type $1 \mathrm{DM}$, the finding of increased expression of TGFBIp in podocytes argues for a role for increased 
GH-dependent TGFBIp expression in the pathogenesis of podocyte injury in DM.

In summary, our studies indicate that GH induced apoptosis and EMT in part mediated by GH-dependent increase in TGFBIp expression. We did not find any significant increase in IGF-1 expression in both GH treated podocytes and glomerular preparation from GH injected rats (data not shown). Earlier studies also reported that there was no increase in renal IGF-1 in GH injected rats [Landau et al., 2003] and in mice transgenic for GH [Doi et al., 1990]. Taken together, the data suggest that the deleterious effect of GH on renal function is independent of IGF-1. The present study adds support for a role for increased circulating levels of GH in the pathogenesis of DN in type 1 DM. We speculate that blockade of TGFBIp could be a novel approach to prevent podocyte damage and disease progression in DN.

\section{ACKNOWLEDGMENTS}

We acknowledge Department of Science and Technology, India for providing research grants IFA11-LSBM-02 and SB/FT/LS-307/2012 (to PAK) and SR/WOS-A/LS-474/2013 (fellowship to PSC).

\section{REFERENCES}

Aaltonen P, Luimula P, Astrom E, Palmen T, Gronholm T, Palojoki E, Jaakkola I, Ahola H, Tikkanen I, Holthofer H. 2001. Changes in the expression of nephrin gene and protein in experimental diabetic nephropathy. Lab Invest 81:1185-1190.

Anil Kumar P, Welsh GI, Saleem MA, Menon RK. 2014. Molecular and cellular events mediating glomerular podocyte dysfunction and depletion in diabetes mellitus. Front Endocrinol (Lausanne) 5:151.

Bae JS, Lee SH, Kim JE, Choi JY, Park RW, Yong Park, Sohn HS, Lee YS, Bae DS, Lee, Kim E, . 2002. Betaig-h3 supports keratinocyte adhesion, migration, and proliferation through alpha3beta1 integrin. Biochem Biophys Res Commun 294:940-948.

Baldelli R, De Marinis L, Bianchi A, Pivonello R, Gasco V, Auriemma R, Pasimeni G, Cimino V, Appetecchia M, Maccario M, Lombardi G, Pontecorvi A, Colao A, Grottoli S. 2008. Microalbuminuria in insulin sensitivity in patients with growth hormone-secreting pituitary tumor. J Clin Endocrinol Metab 93:710-714.

Christiansen JS, Gammelgaard J, Orskov H, Andersen AR, Telmer S, Parving HH. 1981. Kidney function and size in normal subjects before and during growth hormone administration for one week. Eur J Clin Invest 11:487-490.

Cummings EA, Sochett EB, Dekker MG, Lawson ML, Daneman D. 1998. Contribution of growth hormone and IGF-I to early diabetic nephropathy in type 1 diabetes. Diabetes 47:1341-1346.

Doi T, Striker LJ, Gibson CC, Agodoa LY, Brinster RL, Striker GE. 1990. Glomerular lesions in mice transgenic for growth hormone and insulinlike growth factor-I. I. Relationship between increased glomerular size and mesangial sclerosis. Am J Pathol 137:541-552.

Edge JA, Dunger DB, Matthews DR, Gilbert JP, Smith CP. 1990. Increased overnight growth hormone concentrations in diabetic compared with normal adolescents. J Clin Endocrinol Metab 71:1356-1362.

El Nahas, Cope AH, Le Carpentier GH, . 1991. Role of growth hormone in the development of experimental renal scarring. Kidney Int 40:29-34.

Gilbert RE, Wilkinson-Berka JL, Johnson DW, Cox A, Soulis T, Wu LL, Kelly DJ, Jerums G, Pollock CA, Cooper ME. 1998. Renal expression of transforming growth factor-beta inducible gene-h3 (beta ig-h3) in normal and diabetic rats. Kidney Int 54:1052-1062.
Han JH, Ha SW, Lee IK, Kim BW, Kim JG. 2010. High glucose-induced apoptosis in bovine retinal pericytes is associated with transforming growth factor beta and betaIG- H3: betaIG-H3 induces apoptosis in retinal pericytes by releasing Arg-Gly-Asp peptides. Clin Experiment Ophthalmol 38: 620-628.

Kalani A, Mohan A, Godbole MM, Bhatia E, Gupta A, Sharma RK, Tiwari S. 2013. Wilm's tumor-1 protein levels in urinary exosomes from diabetic patients with or without proteinuria. PLoS ONE 8:e60177.

Kannabiran C, Klintworth GK. 2006. TGFBI gene mutations in corneal dystrophies. Hum Mutat 27:615-625.

Kim JE, Kim SJ, Jeong HW, Lee BH, Choi JY, Park RW, Park JY, Kim IS. 2003a. RGD peptides released from beta ig-h3, a TGF-beta-induced cell-adhesive molecule, mediate apoptosis. Oncogene 22:2045-2053.

Kim MO, Yun SJ, Kim IS, Sohn S, Lee EH. 2003b. Transforming growth factorbeta-inducible gene-h3 (beta(ig)-h3) promotes cell adhesion of human astrocytoma cells in vitro: implication of alpha6beta4 integrin. Neurosci Lett 336:93-96.

Kolset S0, Reinholt FP, Jenssen T. 2012. Diabetic nephropathy and extracellular matrix. J Histochem Cytochem 60:976-986.

Kumar PA, Brosius FC, Menon 3rd, . 2011. The glomerular podocyte as a target of growth hormone action: Implications for the pathogenesis of diabetic nephropathy. Curr Diabetes Rev 7:50-55.

Kumar PA, Chitra PS, Reddy GB. 2013. Metabolic syndrome and associated chronic kidney diseases: Nutritional interventions. Rev Endocr Metab Disord 14:273-286.

Kumar PA, Kotlyarevska K, Dejkhmaron P, Reddy GR, Lu C, Bhojani MS, Menon RK. 2010. Growth hormone (GH)-dependent expression of a natural antisense transcript induces zinc finger E-box-binding homeobox 2 (ZEB2) in the glomerular podocyte: A novel action of gh with implications for the pathogenesis of diabetic nephropathy. J Biol Chem 285:31148-31156.

Landau D, Israel E, Rivkis I, Kachko L, Schrijvers BF, Flyvbjerg A, Phillip M, Segev Y. 2003. The effect of growth hormone on the development of diabetic kidney disease in rats. Nephrol Dial Transplant 18:694-702.

Li Y, Kang YS, Dai C, Kiss LP, Wen X, Liu Y. 2008. Epithelial-to-mesenchymal transition is a potential pathway leading to podocyte dysfunction and proteinuria. Am J Pathol 172:299-308.

Ma C, Rong Y, Radiloff DR, Datto MB, Centeno B, Bao S, Cheng AW, Lin F, Jiang S, Yeatman TJ, Wang XF. 2008. Extracellular matrix protein betaig-h3/ TGFBI promotes metastasis of colon cancer by enhancing cell extravasation. Genes Dev 22:308-321.

Manelli F, Bossoni S, Burattin A, Doga M, Solerte SB, Romanelli G, Giustina A. 2000. Exercise-induced microalbuminuria in patients with active acromegaly: Acute effects of slow-release lanreotide, a long-acting somatostatin analog. Metabolism 49:634-639.

Mason RM, Wahab NA. 2003. Extracellular matrix metabolism in diabetic nephropathy. J Am Soc Nephrol 14:1358-1373.

Nakamura T, Ushiyama C, Suzuki S, Hara M, Shimada N, Ebihara I, Koide H. 2000. Urinary excretion of podocytes in patients with diabetic nephropathy. Nephrol Dial Transplant 15:1379-1383.

Nummela P, Lammi J, Soikkeli J, Saksela 0, Laakkonen P, Holtta E. 2012. Transforming growth factor beta-induced (TGFBI) is an anti-adhesive protein regulating the invasive growth of melanoma cells. Am J Pathol 180: 1663-1674.

Reddy GR, Pushpanathan MJ, Ransom RF, Holzman LB, Brosius FC, Diakonova 3rd, Mathieson M, Saleem P, List MA, Kopchick E0, Frank JJ, Menon SJ. 2007. Identification of the glomerular podocyte as a target for growth hormone action. Endocrinology 148:2045-2055.

Sato Y, Wharram BL, Lee SK, Wickman L, Goyal M, Venkatareddy M, Chang JW, Wiggins JE, Lienczewski C, Kretzler M, Wiggins RC. 2009. Urine podocyte mRNAs mark progression of renal disease. J Am Soc Nephrol 20:1041-1052. 
Shankland SJ. 2006. The podocyte's response to injury: Role in proteinuria and glomerulosclerosis. Kidney Int 69:2131-2147.

Skonier J, Neubauer M, Madisen L, Bennett K, Plowman GD, Purchio AF. 1992. CDNA cloning and sequence analysis of beta ig-h3, a novel gene induced in a human adenocarcinoma cell line after treatment with transforming growth factor-beta. DNA Cell Biol 11:511-522.

Thapa N, Kang KB, Kim IS. 2005. Beta ig-h3 mediates osteoblast adhesion and inhibits differentiation. Bone 36:232-242.

Tonshoff B, Veldhuis JD, Heinrich U, Mehls O. 1995. Deconvolution analysis of spontaneous nocturnal growth hormone secretion in prepubertal children with preterminal chronic renal failure and with end-stage renal disease. Pediatr Res 37:86-93.

Verzola D, Gandolfo MT, Ferrario F, Rastaldi MP, Villaggio B, Gianiorio F, Giannoni M, Rimoldi L, Lauria F, Miji M, Deferrari G, Garibotto G. 2007. Apoptosis in the kidneys of patients with type II diabetic nephropathy. Kidney Int 72:1262-1272.

Ween MP, Lokman NA, Hoffmann P, Rodgers RJ, Ricciardelli C, Oehler MK. 2011. Transforming growth factor-beta-induced protein secreted by peritoneal cells increases the metastatic potential of ovarian cancer cells. Int J Cancer 128:1570-1584.

Ween MP, Oehler MK, Ricciardelli C. 2012. Transforming Growth FactorBeta-Induced Protein (TGFBI)/(betaig-H3): A Matrix Protein with Dual Functions in Ovarian Cancer. Int J Mol Sci 13:10461-10477.

Wolf G, Chen S, Ziyadeh FN. 2005. From the periphery of the glomerular capillary wall toward the center of disease: Podocyte injury comes of age in diabetic nephropathy. Diabetes 54:1626-1634.

Zamilpa R, Rupaimoole R, Phelix CF, Somaraki-Cormier M, Haskins W, Asmis $\mathrm{R}$, LeBaron RG. 2009. C-terminal fragment of transforming growth factor beta-induced protein (TGFBIp) is required for apoptosis in human osteosarcoma cells. Matrix Biol 28:347-353.

\section{SUPPORTING INFORMATION}

Additional supporting information may be found in the online version of this article at the publisher's web-site. 